\title{
Opinion: creativity on fashion
}

\section{Opinion}

I've been fortunate to be working in a field that is something that I not only really love, but have a strong point of view and am able to share this opinion through my work and my teaching. Having an opinion may be the most important part about being an artist. Yes, you must have skills, talents and passion, but if you do not have a point of view, an opinion then you are just doing artwork... you are not an artist. Being a creative, I express myself in many ways and I think anyone who creates should be able to do this to show the world their opinion.

\section{Creativity: "seeing the signs"}

I was recently contacted by a former student and asked about my thoughts on creativity. It's interesting as I felt she was one of the more creative students that I have taught and I even mentioned this to her in class at one point. There were particular things that I saw, that I've seen in other creatives that I've known. The main thing was the ability to expand her thought process in an algebraic way... meaning she would latch onto a concept and it would lead to a new thing, then another, then another. To me this may be one of the most important things to recognize if you are tasked with any creative problem. It can also be one of the most daunting and difficult things to try and contain.

She mentioned that she felt that problem solving was synonymous with creativity and I have long believed this concept. In fact, I don't think of myself so much as an artist as I do a person who uses creativity to solve visual problems. While working with her I noticed a few more things that seemed to be hindering her. First, she seemed overwhelmed by all the directions of her thoughts. Anyone who has embraced the idea that they are creative struggle with this problem. I've struggled with it for my entire life, but learned in college to reign in my wandering mind. There must be some compartmentalization of the thoughts and ideas. I use lots of notebooks and iPhone apps to take notes and sketches. This is being written in Ever note so I can add \& edit anywhere. The act of "expulsion" of the ideas helps me clear out the clutter, so to speak.

Next was her struggle with decision making. I believe that anything really good that you create does not just pop out of you... it develops. When instructing my students and I task them with creating concepts for something I always ask them to show me 3 or 4 options. Even if you have the concept in your head, pushing yourself further always leads to something good... even if that discovery is something which seems small and insignificant. I like to say, "If asked to do 3 or 4 concepts I always do 5 and inevitably it's the 6th one that works!" I've digressed a bit... All that is fine, but if you cannot DECIDE which one solves your problem or is the most visually pleasing, it does not matter. So CHOOSE. You're the designer; pick the one you like best. Remember this when choosing; there is not really a right or wrong answer as it relates to solving your own creative problems.

Finally the thing that I saw which excited me the most was her willingness to experiment and explore. If you are open to new things and able to absorb what you find and add it to your arsenal for creative problems, then you'll be able to solve any problem. Personally I think this is where being coined a "genius" can be limiting... but that is my next post.
Volume 3 Issue 3 - 2017

James T Simon
Parsons Fashion, New school University, USA

Correspondence: James T Simon, Assistant Professor, Parsons Fashion, New school University, USA, Emailsimonj@newschool.edu

Received: October 03, 2017 | Published: November 22, 2017

\section{Creativity: "genius"}

Genius |'jēnyəs| noun (pl. geniuses)

a. Exceptional intellectual or creative power or other natural ability: she was a teacher of genius | Gardner had a real genius for tapping wealth.

b. A person who is exceptionally intelligent or creative, either generally or in some particular respect: one of the great musical geniuses of the 20th century.

By the definition above, I guess I'm a genius. Personally I don't like the word genius. My parents have embraced technology and I've shown them how much easier Apple products are to use. On a weekly basis my mother and I will engage in "geek sessions" so I can help her. I enjoy them... it allows us to connect more. When we started these sessions she called me her "genius". I jokingly said, "I prefer the term 'guru'." She chuckled at that and she now calls me that. "I need a geek session, guru."

$\mathrm{Gu} \cdot \mathrm{ru}$

('goər u, go'ru) n., pl. -rus.

i. A preceptor giving personal religious or spiritual instruction, esp. in Hinduism.

ii. Any person who counsels or advises; mentor.

iii. A leader in a particular field: the city's cultural gurus.

These definitions are quite literal. I personally like the concept of what the term means in Sanskrit; "Guru" literally indicates the dispelling of darkness. "The syllable gu means shadows, The syllable $\mathrm{ru}$, he who disperses them. Because of the power to disperse darkness the guru is thus named." I like to think that when I am able to give knowledge that I have, I am dispelling the darkness of ignorance, bringing light to new understanding.

I enjoy watching the TV show "The Big Bang Theory". The humor is smart, the characters are likable, it's not gratuitous and when it's not funny it is sweet or poignant. I think we're more like these characters than those in other shows as they struggle with social problems. I identify with them as they're different than most people.

In one particular episode they compete in a contest where they must answer physics questions. At the end of the episode, Penny holds 
her own mini contest and asks Leonard \& Sheldon "People Magazine questions" about celebrities and popular culture. None of which the boys get right and they're amazed at her knowledge of these things. I think this is an interesting scene as it shows that although the boys are geniuses, they're only book smart. Penny has her own level of genius. I think this is an interesting point.

I'm not much of a fan of any type of classification (what type of art do you do, what movies do you like, music, etc.). I like what I like. People are people. We all know different things. There are those that stand out through history as making larger contributions to their lives. Leonardo, Mozart, Nietzsche, Hawking. But I'm sure they all lacked knowledge in something. Wonder if anyone ever called Steve Jobs a genius? Einstein obviously didn't know fashion! As I am working through this, I came across this quote by Bruce Lee which I think is something we should all think about as we're wondering about what we know and how we can use it.

My hope is that those to whom I am able to give whatever knowledge I have will, in turn, do the same if in the same situation so that others can be brought out of the darkness of their ignorance. Let's all aspire to be gurus, rather than geniuses.

\section{Creativity: "expression"}

Expression is both the best and worst part about being a creative. For me, the act of creating anything gives me a physical high. I feel lighter and have more energy. I'm satisfied that I've used my talents to put something beautiful out into the world. Some people become doctors or philanthropists... I like to say that what I give back to the world is my creativity.

I carry a sketchbook wherever I go. I make an effort to spend time sketching rather than staring at my phone. (Ugh, so much of that going on now.)

I feel fortunate that I have two careers that allow me to use my creative talents and that the work I truly love, the work I do for myself, the way I express myself (words, music, art) are just that; MY expressions. I put my work out there and sometimes people comment.
What can be difficult is the criticisms of others as related to your work. The first thing you need to accept is that criticism is good. Getting someone else's perspective on anything can be helpful... IF the person giving it knows how to critique without being simply mean. If you learn that by being open to criticism, your work can improve. Hopefully the critic will be objective and not attack you personally as THAT can be difficult.

Being asked to give criticism on anything creative is difficult if the creator is lukewarm about the work. I believe that creating anything is intensely personal. Not only is the physical act of putting "pencil to paper" something that takes talent, but showing other people can be absolutely terrifying, but you need to love it. You need to fight for it. You need to make the viewer believe that what you created is truly beautiful. Your work is your point of view and if you do not have passion about your point of view, why are you looking for criticism.

Try not to fear that people will not like your work. The trick I use is that it is MY work and they may not understand. If I'm putting it out there and looking for input, I must help the viewer understand. My philosophy is that art should be accessible, easy to understand, but the creator should be willing to help those who do not understand see what they are trying to convey. Whether you paint, draw, write stories or music you invite others to view part of your soul and that can be difficult, but I highly recommend it.

\section{Acknowledgements}

None.

\section{Conflict of interest}

Author declares there is no conflict of interest in publishing the article.

\section{References}

1. James T Simon. This article originally appeared in 3 parts on the blog. 2015. 